\title{
CARLOS FUENTES Y SU CONCEPTO DE LA NOVELA
}

\author{
Por \\ LUIS DÁVILA \\ Indiana University
}

Clara, entendible y bien explicable. Sin embargo, esta novela es demasiado pedestre. Su lectura, muy accesible. Se puede compartir fácilmente y agotar en forma un tanto conclusiva. Se cierra como un estuche. Su historia, simple. Su estructura, lineal. Su lenguaje, prosaico. Hay algo en ella que no es moderno, que hoy no funciona. Especialmente, si tomamos en cuenta que Cervantes desde hace algún tiempo escribió el Quijote.

Todo lo de arriba bien podríamos exclamar después de confrontar una novela como Las buenas conciencias, la cual Octavio Paz ha caracterizado como un "intento poco afortunado de regreso al realismo tradicional". ${ }^{1} \mathrm{Y}$ en efecto, la segunda novela de Fuentes tiene cierto dejo galdosiano, sin embargo para algunos lectores esto resulta como bonanza narrativamente útil y hasta benéfica, pues el entendimiento de la obra procede en forma directa $\mathrm{e}$ inmediata. Al terminar de leer esta novela sabemos lo que nos quería decir el autor en torno a la mezquindad de las buenas conciencias en un pueblo tradicional y provinciano, tal como lo hizo Galdós en Doña Perfecta usando semejantes pinceladas maniqueístas. Con todo, aún admitiendo la claridad caricaturesca del mundo guanajuatense descrito en la novela de Fuentes, habría que notar que también hay en ella ironías, permutaciones de personajes, hondo lirismo, pujanza narrativa, posición ideológica y cierta circularidad estructural. Estos rasgos, que también podemos encontrar en mucha de la novelística de Fuentes, no distan mucho, en lo fundamental, de los que hallamos en Terra Nostra, la caja de Pandora por excelencia. ${ }^{2}$

Las buenas conciencias termina con el retorno del protagonista a la vieja casa ancestral: "Caminó de regreso a la casa de los antepasados. Había salido

\footnotetext{
I Octavio Paz, "La máscara y la transparencia", prólogo a Carlos Fuentes: cuerpos y. ofrendas (Madrid: Alianza Editorial, 1972), p. 8.

2 José Miguel Oviedo, en "Fuentes: sinfonía del Nuevo Mundo", Hispamérica, 6, No. 16 (1977), 19-32, señala que en Terra Nostra Fuentes se propone "escribir una enciclopedia de su propio saber novelístico en la que cabe todo lo que le procupa, ama, detesta, desea, recuerda". Y añade Oviedo: "el esplendor verbal es tan intenso que parece anunciar el silencio: ha puesto allí [Fuentes] tantas cosas que uno teme se haya quedado vaciado". (p. 19).
} 
a la una y Guanajuato le devolvía un reflejo violento desde las cúpulas y las rejas y los empedrados. La mansión de cantera de la familia Ceballos abría su gran zaguán verde para recibir a Jaime". Estas mismas palabras había puesto Fuentes antes del comienzo del primer capítulo, y al terminar con ellas hace que la serpiente de la simultaneidad se muerda la cola una vez más. Antiguo y consabido recurso, el de hacer que el lector regrese al punto narrativo de partida, y efectivo porque al volver ya le ha pasado la historia, la lectura, el discurso, y ahora el principio es discursivamente reconocible. El comienzo está cargado de significado, tal como en Terra Nostra ese último volver a lo que fue el principio de la narración es verdaderamente significativo. Cuando iniciamos la lectura de Terra Nostra no percibíamos claramente el París apocalíptico de 1999 en el cual nos encontrábamos, pero sí lo reconocemos al zambullirnos en él al concluir la novela. Las lecturas posibles en estas dos obras de Fuentes son similares en el sentido de que ambas son tanto circulares en su estructura como lineales en su temporalidad discursiva. Es decir, su lectura ocurre en el tiempo, y la dinámica de esa lectura se realiza en forma lineal. El proceso en ambas es similar. Sin embargo, la idea de que una novela contemporánea se lea como algo sacado de Balzac, Galdós, Rómulo Gallegos, o José Eustacio Rivera, o que en forma alguna tenga las cualidades clarificativas de las epopeyas orales o de los romances antiguos, nos hace sentirnos un poco incómodos a los lectores modernos.

¿Por qué será así? ¿Por qué reacciona mos ante novelas que a primera vista parecen ser sencillas, como si fueran por consecuencia simplistas o unívocas? El Quijote después de todo no es, a fin de cuentas, una novela difícil, y aunque tenga varios niveles de lectura, todos son accesibles al lector común. De la misma manera así lo es Cien años de soledad, aún con sus múltiples mitologías. Y a pesar de que Fuentes caracteriza el Poema del Cid como un "stark, bellicose epic of Christian Spain", ${ }^{3}$ que lleva una visión unívoca, hay lectores que bien pueden experimentar en la lectura de este poema medieval algo altamente más complejo. Pues si el texto antiguo hasta cierto punto nos llega vaciado de su contexto, por otro lado el lector trae consigo un polivalente contexto contemporáneo. Esto Walter Slatoff bien nos lo ha recordado recientemente, aclarando: "This sort of filling in or rounding out is very different from the loose speculation, daydreaming or psychologizing about the lives and motives of fictional characters that so irritates anyone who believes that reading must at least be guided and limited by the text. . . That this phenomenon does occur, that we must in some respects move beyond the

\footnotetext{
${ }^{3}$ Carlos Fuentes, Don Quixote, Or the Critique of Reading (Austin: Institute of Latin American Studies, 1976), p. 28. La versión castella na, que no pude conseguir, se titula Cervantes ola crítica de la lectura (México: Joaquín Mortiz, 1976).
} 
text, of course makes it very difficult to determine just what constitutes a valid reading". ${ }^{4}$ Entonces habrá ocasiones en las cuales la lectura común bien podría ser tan aceptable como la estudiada, y ésta es parte de la razón por la cual el lector laico bien podrá leer textos medievales con amplia satisfacción narrativa. El Poema del Cid es accesible porque sus rastros medievales no le imponen al texto una visión unívoca del mundo. El texto mismo bien nos puede incitar a una lectura abierta, porque refleja valores e ideales que trascienden lo medieval. Si así no fuera, el poeta de Medinaceli viviend o en un mundo sumamente autoritario, no podría haber escrito: “iDios, que buen vasallo, si oviesse buen señore!" Ni podría haber llevado al Cid, leal y creyente, a la puerta de una niña asustada que rechaza a su mayor con sólo el buen sentido: "Non vos osíemos abrir nin coger por nada." Lo que bien podría parecer de primero una visión unívoca en el Poema del Cid es en realidad algo más complejo, y esto se debe a las distintas lecturas posibles, dadas las obvias aperturas textuales. De la misma manera, algunas de las lecturas que podríamos hacer de La vorágine o de Doña Bárbara no tienen que ser simplistas. La riqueza emotiva y la ambigüedad moderna son cualidades que también el lector mismo, laico o profesional, puede traer a los textos. Las historias amplias y los buenos narradores suelen permitirnos mucho campo interpretativo. Por ello, cabe preguntarnos por qué molestan a algunos lectores, las estructuras lineales, los aspectos denotativos o las visiones del mundo que nos dan un claro enfoque realista o histórico.

Valdría consultar en esto a Carlos Fuentes, pues como creador y crítico ha sido un estimulante y hábil comentador de la novela moderna. Sus ensayos sobre la novela: La nueva novela hispanoamericana (1969), Casa con dos puertas (1970) y Cervantes o la crítica de la lectura (1976), junto con las entrevistas de Rodríguez Monegal, Rita Guibert, Bill Moyers y otros, han sido altamente útiles para apreciar el Boom de la novela hispanoamericana. Gracias a sus explicaciones discursivas del arte de novelar sabemos que al escribir sus novelas tiene presente tanto la historia denotativa como la literatura connotativa. Sin embargo como el Melquíades de García Máquez o como el Cide Hamete Benengeli de Cervantes, el típico narrador de Fuentes, "nos niega las comodidades de pensar que la narración es un ente autónomo o que la ficción refleja la realidad inmediata". ${ }^{5}$ La lectura de la novela de Fuentes siempre implica la crítica de índole denotativa. Sus narradores y protagonistas meditan sobre los fines histórico-sociales de la literatura. Ensayan y meditan en forma discursiva. Esto lo podemos comprobar en

\footnotetext{
${ }^{4}$ With Respect to Readers (Ithaca and London: Cornell University Press, 1970), pp. 17-18.

${ }^{5}$ Carlos Fuentes, "Muerte y resurrección de la novela novela", en Casa con dos puertas (México: Joaquín Mortiz, 1970), p. 79.
} 
Javier y el narrador de Cambio de piel, en el Señor de Terra Nostra y en el narrador Trevor/Mann/Timón de Atenas de La cabeza de la hidra. Desde La región más transparente hasta Una familia lejana al leer a Fuentes nos encontramos con una mente que critica tanto el arte como el mundo en forma discursiva. "Every novel has criticized the world", afirma Fuentes a Bill Moyers, "because it has criticized itself first of all. So, in all my novels what I have is a double criticism: a criticism of the novel itself, of its assumptions, of its hypotheses, of the way it is done. I criticize this from within the novel, and at the same time I am trying to criticize the world and history". ${ }^{6}$

Hay otros asuntos que debemos considerar al examinar el concepto de la novela que ha postulado Carlos Fuentes a través de los años. Habría que recordar que al publicar La nueva novela hispanoameriana en 1969 Fuentes insiste en la necesidad de experimentar con el mito, el lenguaje y la estructura novelesca. ${ }^{7}$ Esta trinidad pasó a ser una especie de piedra de toque para cierta crítica literaria que se empeñó demasiado en buscar lo novedoso en el lenguaje, lo inefable y misterioso en los mitos y la complejidad en las estructuras. La crítica a veces se volvió más rebuscada que las nuevas novelas, y lo más lamentable de este fenómeno fue el olvido al cual se condenó la dinámica de la lectura, la subjetividad del lect or que forja en parte su texto, $\mathrm{y}$ al texto mismo que organiza en forma discursiva las vivencias del lector sin la mediación de un lector intermediario. El propio Fuentes había escrito en 1970: "Tanto Cervantes como García Márquez proponen otro problema, sus libros no han de ser creídos, sino leídos, su realidad es la lectura; pero sólo gracias a la lectura el saber conoce, pone en duda y traspasa las fronteras de lo que pasa por "la realidad'a fin de ingresar al infinito de lo real". ${ }^{8}$ Es así como el novelista nos llama la atención a la discrepancia que existe entre un conocimiento crítico de la realidad novelística, según se le explica o se le da al lector para que crea en la obra, y la experiencia de la propia lectura por medio de la cual se atraviesa en forma afectiva el territorio del texto mismo. Y si ha de haber exégesis crítica los novelistas también quieren ponerse al servicio del lector. Es decir, Fuentes, Goytisolo, Vargas Llosa y otros, le siguen la pauta a Paz, y salen a la plaza pública para explicar la literatura, y hasta cierto punto a rescatarla de la crítica académica. 9 Por medio de sus ensayos, Fuentes

\footnotetext{
6"The Many Worlds of Carlos Fuentes", Bill Moyers'Journal, Library No. M-46, Show No. 520 , p. 12.

${ }^{7}$ La nueva novela hispanoamericana (México: Joaquín Mortiz, 1969), p. 20.

${ }^{8}$ Casa con dos puertas, p. 79.

9 Michael Hamburger observa este fenomeno: "Very few, if any, serious poets since Baudelaire have been able to make a living out of their work: but thousands of people including poets themselves, have made a living by writing or talking about poetry". The Truth of Poetry (New York: Harcourt Brace Javanovich, 1969), p. 2.
} 
irónicamente toma el camino discursivo para insistir que dejemos la crítica de la novela al artista que escribe y al lector que simplemente lee. La lectura crítica entonces debe de pasar a los que están aislados de las capillas, o sea a los herejes que están fuera de la academia. Desde 1969 venía afirmando Fuentes esto: "El 'street fighting man' de los sesentas también siente 'sympathy for the devil'. La herejía de Pelagio volvió a levantar cabeza contra todas las iglesias; los hombres, en los sesenta, para los setentas, reclamaron la gracia sin intermediarios. Algunos novelistas no fueron insensibles a estas trasformaciones. Algunos, hasta las habían anunciado". ${ }^{10}$ Tal como Pelagio el hereje que, contra San Agustín se empeñó en salvar su alma sin la mediación de la iglesia, así el autor conjeturado por Fuentes quiere ir directamente al lector para solucionar el texto con él, por medio de la lectura, y sin intermediarios académicos. "El lenguaje es," nos dice Fuentes, "por definición, creación colectiva. Pero la cristalización sincrónica requiere, para no petrificarse en la estructura, la constante renovación del habla, el discurso, el proceso y el evento de la palabra"." La gran importancia del residuo oral en la escritura es algo que Fuentes aprendió bien de Alfonso Reyes, y en parte es lo que lleva al lector, vez tras vez, a participar en el discurso de los textos de Fuentes. El autor es un gran narrador que nunca olvida los consejos de Reyes en cuanto a la importancia del discurso oral:

Eso que leemos en los libros no es el idioma, sino el retrato o reflejo de un solo momento del idioma. Es la fría ceniza que cae de la combustión de la vida. Es como la huella de los idiomas. Mas éstos siguen adelante, y van caminando según las flexiones que les comunica el habla familiar. Y, como la gente culta tiene la superstición de las formas establecidas; como se ha enfriado en ella el don de hablar; .... se va enseñando a repetir iguales palabras e iguales giros, y prolonga así un filón de lengua fósil en el torbellino hirviente del idioma. Sólo el populacho tiene el valor de innovar, de pronunciar mal, de ir haciendo mudarse los giros y las expresiones. Así les da vida. ${ }^{12}$

Fuentes ha reconocido esto en forma cabal y por ello ha logrado capacitar a sus protagonistas y narradores con ese "don de hablar" esencial al discurso.

Si el acto de leer se puede equiparar al acto discursivo, entonces habría que enmarcarlo en un esquema temporal como sugiere Lucille Kerr en un reciente trabajo sobre Terra Nostra. Alli afirma que "language marks time, and reading and writing are temporally organized activities, as Fuentes in fact

${ }^{10}$ Casa con dos puertas, p. 85.

1 Casa con dos puertas, p. 79-80.

12 "De la lengua vulgar", en Antología de Alfonso Reyes (México: Fondo de Cultura Económica, 1963), p. 65. 
recognizes (Coddou, p. 9: cf. n. 10). Since the linearity and forward movement of language on the written page can be negated only illusorily, Fuentes must make an elaborate and forceful effort to suppress that fact within Terra Nostra". ${ }^{13}$ ¿Y qué es el aspecto lineal de cualquier texto? Es el mínimo hilo discursivo sustentado por cualquier historia, si es que se le pueda entender en forma alguna. Las novelas de Fuentes siempre conllevan cierta linealidad atenuada, que varía pero que de todos modos siempre existe. Todo paciente lector de Fuentes puede encontrarle sus hilos narrativos, por más circulares o simultáneas que parezcan sus estructuras. Las historias cuando complejas, se despliegan de tal forma que cada aparente recontar es una amplificación de la historia. Terra Nostra que es la novela menos lineal de Fuentes es a la vez la crítica definitiva de la novela caja de Pandora. Su realidad fictiva depende de nuestra afinidad por la lectura discursiva que pudiera explicar la obra y darle sentido. Sin este deseo constante no habría lectura.

No nos sorprende entonces que Fuentes diga que Cervantes o la crítica de la lectura es una guía para la lectura de su Terra Nostra. Esta novela tiene un gran parentesco con el Quijote, en el sentido de que ambas tratan de liquidar un previo mundo literario de lo fantástico. La una, el mundo de las novelas de caballería. La otra, el de la novela del Boom. Es posible que ahora se pueda estrenar una novela menos olímpica, más lineal y narrativamente más accesible al lector común. La penúltima novela de Fuentes, La cabeza de la hidra, parece llevar esta dirección. Es posible que se escriban otras novelas en forma de caja de Pandora, pero valdría cuestionar si todavía tendrían vigencia. La cabeza de la hidra retiene lo mejor de la a mbigüedad de la novela anterior de Fuentes, conservando ciertas cualidades circulares. Deja algunas preguntas suscitadas por el argumento, sin contestar, pero sí nos absorbe en su drama narrativo como si fuera una buena novela de Dashiel Hammitt con un múltiple perspectivismo que nunca pierde su hilo discursivo. Esta novela de espías de Fuentes exige que el lector siga la historia narrativa, que repugne a los malos, enderece injusticias y experimente el ideal del amor. Es una novela sencilla y maniqueísta, en cierta manera. Tiene dos temas centrales que son los mismos que Fuentes identifica como los principales del Quijote: el amor y la justicia. Estas son las dos pasiones que encontramos en toda la novelística de Fuentes, sea lineal, circular o las dos. Ni más, ni menos.

\footnotetext{
${ }^{13}$ Lucille Kerr, "The Paradox of Power and Mystery: Carlos Fuentes' Terra Nostra," PMLA, 95, No. 1 (enero de 1980), 99.
} 